\title{
Negotiating the Moral Education of Medical Students in the Age of Multiculturalism
}

\author{
Paul A. Komesaroff \\ Monash University, Centre for Ethics in Medicine and Society, Global Reconciliation, Melbourne, Australia \\ Email: paul.komesaroff@monash.edu
}

Received 2 March 2015; accepted 20 March 2015; published 24 March 2015

Copyright (c) 2015 by author and Scientific Research Publishing Inc.

This work is licensed under the Creative Commons Attribution International License (CC BY). http://creativecommons.org/licenses/by/4.0/

(c) (i) Open Access

\begin{abstract}
Formal teaching of ethics in medical courses has failed, providing little more than a vehicle for recapitulating conventional theories and reinforcing social prejudices. Courses are most typically based on out-dated and partial hyper-rationalistic theories that bear little relevance to the tasks of decision making in actual clinical life and on outmoded educational theories. A more adequate approach must recognise two paradoxes. First, the educational process in medicine has to be both limiting and enabling: it must control behaviours, characters and interpersonal styles, and it must achieve exactly the opposite, by establishing the possibility of responding to novel situations and inventing original solutions to ethical uncertainties. Second, despite the extreme complexity of ethical encounters and cultures, communication among contending discourses is always possible; indeed, the more profound the gulf is, the richer and more fecund the play of differences that constitute the dialogue can become. The multiple, diverse tasks of ethics are linked to contrasting technologies and pedagogies. In recognition of this, this article highlights the need for educational approaches in medicine that do not only reproduce the moral assumptions and prejudices of the mainstream culture but also are faithful to the actual practices of clinical decision making, thereby contributing to the cultivation of multidimensional competencies covering many levels of personal and social experience.
\end{abstract}

\section{Keywords}

Ethics, Moral Education, Medicine, Multiculturalism, Postmodernism

\section{Introduction}

It has always been hard to teach people to be ethical. It is harder than ever when the system is corrupt, the world is full of injustice, and there is no longer any agreement about core values, goals or responsibilities. 
This is the predicament that confronts medical education. The students enter their medical courses in good faith, albeit with a variety of purposes, and from a great many cultural and religious backgrounds and geographical origins. They encounter patients in public hospitals facing complex ethical choices, often in fraught and difficult circumstances, and they find themselves facing the expectation that somehow they will be able to offer some kind of constructive guidance.

Medicine is an intense and ceaseless conversation across cultures, religions and ethical perspectives, a conversation that traverses the great questions of life and death, as well as the profound divisions in society and culture. It proceeds inexorably and imperfectly, with outcomes that are rarely secure and never satisfactory. The pedagogy is hard, not only because the questions are difficult but also because the experience of seeing someone die before your eyes, of helplessness in the face of suffering, of being a witness to the emptiness of the parent, or child, or spouse, or relative, or friend when the terrible reality can no longer be avoided, is hard.

$* * * * *$

I am with a group of students, doing bedside teaching. We go to see an elderly Moslem man. He has multiple illnesses, which include dementia, cancer and pneumonia. The team at handover has already decided that no treatment is warranted, and that the case is "futile". The man's family, however, do not see it that way. They demand that everything be done that is possible to keep him alive even, as they say, if it is only for a few extra minutes. His daughter - who has been assigned at an early age to care for him in his old age and whose whole life is one of service to her father, brothers and sisters-is frantic. We quickly see that it is not just her father's life that is at stake but hers too. The medical team refuses to accept this and is unmovable. The students observe the debates, the heated discussions and the bitter recriminations.

$* * * * *$

To explain what is at stake it is necessary to reflect briefly the nature and role of ethics in medical practice. The field of thought and action in which I seek to answer the question of what I should do in my practical life is what we refer to as "ethics". Commonly, practical decisions are made in contexts of multiple influences and changing, often uncertain conditions. Ethics does not refer to decision making styles or one or other theory so much as to a domain of thought and action that is marked off from those of knowledge and truth, aesthetics and beauty and spirituality and religion (Komesaroff, 2014a; Komesaroff, 2014b).

We cannot avoid ethical decisions. In fact, ethics is everywhere in our personal and professional lives as we go about whatever business we undertake. It is there when we ponder large scale questions about our personal aspirations and goals, and about what drives us forward or holds us back. It is there when we occupy our professional roles, and fulfil the obligations and duties associated with them, and it is there when we interact with a child or a lover, a shopkeeper or a bus driver, or when we engage in a conversation, even of the most casual kind, with a stranger we come across in the street. Ethics imbues our moments of action and reflection with value and meaning. It sets the goals and intentions behind the application of knowledge. It is not purely rational, but nor is it purely affective. It is the practical decision making context that may take its guidance from other modalities of life_-including religion and truth_- but may also in turn help shape their direction.

$* * * * *$

I am with a different group of students. This time the patient is a young man about their age dying of leukaemia. They shuffle about nervously and ask him a few questions about his symptoms and treatments. I ask him directly what it feels like to be dying. He answers blankly that all he can think of is the things he will never do and will never see. He once wanted to complete his studies, to travel the world, to love a woman, but he knows that none of that will now be possible. When he finishes there is silence. As I look around at the students I can see the pain in their faces. They are overcome with pity and sadness, and with the recognition that this young's man's predicament could well be their own.

$* * * * *$

Modern theory in the West - especially in medicine and bioethics - has limited the field of ethics or, at least, its official formulations, to settings in which individual subjects, faced with practical dilemmas, make rational se- 
lections from a range of real or imagined options. This is, however, an incomplete and impoverished characterisation of ethical action, which ignores or omits much of how we engage with others in our personal or professional lives. It is also dependent on a limited, culture-bound, concept of ethical subjectivity and society (Komesaroff, 2014a; Komesaroff, 2014b).

The assumptions of ethical theory are not just limited to a false characterisation of how we make decisions. As Levinas has shown, these assumptions emerge from a mistaken or at least contestable formulation of how the possibility of ethics arises in the first place. In western philosophical thinking, being and subjectivity are assumed to be ontologically prior to all social and affective behaviour. However, it is in reality ethics that is foundational and originary. Ethics is the primary ground on which we come into existence as subjects, as the authors of our own consciousness: it is the condition of possibility of both subjectivity and sociality. Ethics is the starting point, not the secondary phenomenon that needs to be explained. We crystallise as nodal regions of consciousness in a sea of ethical relationships - or rather, it is only logically subsequent to the formation of these nodes that the concept of a relationship itself can become possible (Levinas, 1961).

Ethics is not a monolithic, single body of thought or action. It is highly differentiated and fluid, varying in relation to culture, context and other factors. Its multiple domains cover different areas of life-which themselves have over time become increasingly variable and heterogeneous. We engage with each other on many levels as we negotiate our complex lives through multiple identities.

$* * * * *$

I am sitting in a room of students and young doctors. They are all committed to working in the field of global health, a concept I myself view with suspicion. They speak righteously about poverty and sickness in the developing world, and about the rapaciousness of the developed countries which profit from their dependence. They earnestly intend to do something to change things. From their physical appearance it is evident that their families have come from many parts of the world: from Asia, from Africa, from Europe, the Americas. We are all aware that Australia is a land of immigrants that maintains a massive gulag in which it incarcerates asylum seekers and refugees, without a legal process, often for years. We have just heard on the television a report about a young man who burnt himself to death because he could not bear the threat of repatriation to his native Sri Lanka which he had fled after having been persecuted and tortured there. We have heard that the Australian Government has refused visas for his mother and father to attend his funeral. How do the privileged children of immigrants and refugees come to terms with such contradictions? What can they-or we-do to assuage our collective guilt?

$* * * * *$

The extreme complexity of ethical action somehow has to be both nourished and allowed to flourish, and also controlled and regulated. The ability to negotiate diverse and dangerous fields of conflicting values and intentions evolves naturally as part of the socialisation process: indeed, that is, after all, exactly what "socialisation" means. However, the fostering of the capacity to function in multiple domains - which include professional relationships, with their specific structures and resonances and their changing duties and roles - is also one of the main functions of any regime of medical education (Fox, 1979).

In the theory of moral education it has long been held that the child negotiates a series of stages before reaching the mature status of an adult. Recent theory has reflected critically on the various posited developmental schema, and on the concept that they are ontological stages through which a child inevitably passes, with privileged and clearly defined goals at the end. Instead, they are understood as logical types representing alternative modalities or structures of interaction which can cohere simultaneously in different settings and under different conditions. The completeness of the various extant schematic representations is itself contested, in favour of the idea that they are merely descriptive formulations of cultural or subcultural styles which may be extended or redirected in other settings of culture or gender (Kohlberg, 1984; Habermas, 1976; Gilligan, 1982).

The role of the education system in generating the ability to negotiate the multiple ethical domains of actionwhat we might call "ethical competency"-itself draws attention to a remarkable and irreducible paradox. The educational process has to be both limiting and enabling. On the one hand, it must define the range of possibilities from which choices are possible; it must impose a deep and abiding discipline that controls behaviour, character and interpersonal styles. On the other, it must achieve exactly the opposite: it must establish the possibility of creative variation, of responding to novel situations, of inventing fresh and original solutions to ethical uncer- 
tainties. In other words, moral discourse and moral education must at the same time impose and enforce a disciplinary structure and generate a critical and subversive scrutiny of entrenched systems of meaning and behavioural control.

As we shall discuss below, ethical frameworks are not subject to a principle of incommensurability similar to that which potentially obstructs communication between epistemological systems. Rather, it is of the nature of ethics that difference is the creative resource that opens up new spaces and stimulates new voices, thereby fuelling new possibilities for dialogue. This does not completely invalidate universal principles of moral decision making, but it does limit their applicability to specific domains and to high levels of generality. To the extent that such principles exist, they refer only to large scale conditions of possibility for moral action and have little or no bearing on the actual content of ethical decision making (Irigaray, 1993).

$* * * * *$

Sometimes the conflicting moral tasks are deeply troubling and confusing for the students, as in the case of Nicola, who comes to see me after a stint in the paediatric ward. It is becoming too much for her, she says. Her father is dying of cancer. She herself has just been released from hospital after a bout of depression culminating in a serious suicide attempt. A ward round in which the professor ignored the evident distress of his young patient and her mother was the last straw. The doctor and the students discussed the child and her mother in front of them without even acknowledging their presence. The professor then made an authoritative and peremptory pronouncement, and the group moved on. Nicola, drawing on her own experience, stayed behind after they had left to apologise for the offence to the parent and child. She explains to me that she cannot imagine herself adopting the behavioural mannerisms of the professor - or rather, that she is terrified that she will do so.

$* * * * *$

The paradox is perhaps less surprising than it first seems. The two tasks occur at different logical levels. Ethics is not inherently or fundamentally reflexive. Indeed, spirituality and religion have traditionally provided more systematic resources for reflection on the nature and role of ethics than has ethics itself. However, within the modern framework the certainty and solidity of the old structures of identity and religion have been dislodged, as a result of which the critical and negative aspect has become one of the essential tasks of ethics in its own right (Taylor, 1992).

The modern world is a complicated place. The social issues and choices we face are increasingly complex, as also are the people who make them. There was a time when an entire life's course was laid out at the moment of birth. One was to be a farmer as one's father had been, or a craftsman, or a nun, or a peasant like the many generations before. That started to change around the late Middle Ages. For the first time, the ability to choose gradually emerged - first the idea, then the reality. It is only in very recent times that the possibility of choice has been extended to women, and even then only partially and imperfectly (Heller, 1999).

Along with the expansion of choice has been a proliferation of social roles. We do not just occupy one role today, but many. We are not just a peasant, baker, cobbler, blacksmith, vicar or government official. We are many things simultaneously: we can be a doctor, a teacher, a parent, a researcher, and a social activist, and we can move seamlessly from one role to the other. Even our sexual identities can change.

$* * * * *$

The next patient is odd-bizarre, in fact. She is a transsexual woman who wants to kill herself. She has taken an overdose of paracetamol and presented to the hospital, ostentatiously and triumphantly refusing treatment. She declares that she is a "martyr": a sacrifice to the cause of exposing the cruelty and incompetence of the medical profession, which she blames for her life-long travail. The students are bemused as she regales them with humorous stories about her psychiatric diagnoses, her jousts with medicine and her overflowing pride in the powerful statement she is about to make.

$* * * * *$

Identity in the modern world is fluid and shifting. As Zygmunt Bauman and others have pointed out, we are not just one person: we can be many. We can leave the bank we work for, change into our evening clothes, and be 
transformed as we enter the nightclub, take ecstasy, engage in sexual or other fantasies, and then go back to work again in the morning, as much a reliable employee as the day before (Bauman, 1985).

Even what constitutes an identity has changed. The concept of "homosexuality" did not exist until the eighteenth century. Before that, sexual activity with people of the same sex was just one behaviour among many. The concept of "a homosexual" - of someone whose very being was defined by the nature of one's sexual activityonly came into existence in the twentieth century, and its life span was short; or rather, the way in which that particular identity was assessed and valorised revealed its instability, as a result of which it fluctuates unpredictably between pathology, life choice and genetic predisposition.

This rubs off on the clinic. The young people see themselves in the man dying of leukaemia. Nicola resists the move from her own experience to the controlled and stylised life world of a doctor. The students are fascinated but not scandalised - by the narrative of the transsexual woman.

Religious identities have undergone a similar shift, in some societies but not in all. Once, religion was the broad setting within which the narrative of one's life was articulated. It was the metacontext that defined not one's choices but the framework within which those choices were made. The context came from the community in which one lived, one's family, and on occasions, the law. But religion was not the source of identity. It did not need to play that role. As the all pervasive framework of meaning it was the ground on which identities were constructed.

$* * * * *$

The examples the students see around them are not good ones. The Government has just won an election on the basis of xenophobia-fear whipped up about an invasion of refugees. The Faculty is corrupt. Even the bioethicists are prepared to forego principles and values in favour of personal advancement. Careerism, managerialism, venality are in the ascendancy. The students are dismayed, disabused.

As they learn, they find that the ground beneath their feet gradually begins to feel more uncertain as what they had assumed to be straightforward value frameworks become increasingly unstable and their life tasks less well defined. They may have felt confident at the beginning, coming as they do from backgrounds of education and privilege, of so-called high social capital. However, now they are not so sure. All of a sudden the world, and their place in it, appears less clearly defined.

$* * * * *$

These considerations raise the question of how, through the educational process, we might actively foster the functioning of a system in which young doctors (with multiple identities) come to engage in conversations with patients (with multiple identities) under the guidance of teachers (with multiple identities). Indeed, nowhere is the problem of how to nurture ethical competency more starkly at issue than in medical education, and nowhere is its complexity more starkly evident. This is not only because, like all other professions, medicine is a practice of ethics but because the problems with which it deals on a daily basis encompass all the great questions of life and death. It is also not disconnected from the fact that doctors control considerable power and resources, and the stability of the social institutions requires that they exercise this influence in a reliable and predicable way.

But how does it happen? It is now widely recognised that formal tuition in ethics is at best a minor and ineffectual component of moral education - in medicine or anywhere. It does convey a theoretical capacity to increase awareness of the need for reflective practice. This is, however, hardly ever the case. More commonly, teaching in medical ethics is merely a vehicle for recapitulating conventional theories and reinforcing social assumptions, most typically based on out-dated and partial hyper-rationalistic theories that bear little relevance to the tasks of decision making in actual clinical life (Hafferty \& Franks, 1994; Giroux, 1989; Pellegrino et al., 1985; Eckles et al., 2005; Feudtner \& Christakis, 1994).

More potent as a formative force is the hidden ethics curriculum, to invoke the well-recognised concept from educational theory. The hidden curriculum in ethics education does not, however, refer just to the tacit disciplinary processes embedded within the formal relationships of the teaching program. It encompasses also the ethical style in that characterizes the larger medical community (Hafferty, 1991). This provides the comprehensive and overwhelming set of forces and influences to which all medical neophytes are exposed and by which they are shaped.

We should not forget that —as Jeanne Peterson has shown — the formation of the medical profession itself- 
through the passing of the Medical Act by the British Parliament in 1857-was motivated by the need to standardise education in this field (Peterson, 1978). To put this more precisely, the establishment of the modern profession was effected by a formalisation of the educational process. The latter was not at the time conceived explicitly as ethics education: the focus was rather on social practices not directly linked either to truth or ethics. However, education was understood as the tool by which practices marked as socially approved were protected while all others - including the long-standing craft of midwifery-were branded as superfluous and miscreant.

$* * * * *$

As I write this, a memory recurs to me from the time I myself was a student and one of my most loved and esteemed teachers was dying. I went to visit him in his hospital bed: he had a private room and agreed to see a few of the students he had been mentoring. He knew I was interested in ethics and made an effort on my behalf to reflect on the fact that he was dying. He had found to his dismay that nothing of interest occurred to him. He had always thought, he said, that as death approached he would think grand, momentous thoughts: that insight would form in his mind never before conceived. But it was not like that at all. All he could think of was the pain in his abdomen, his need to urinate, his nausea, his thirst, the itchy lesions on his arms and legs. For him the time of his dying had not expanded grandly to infinity but shrunk pathetically to the moments of his aching head and his next bowel action.

$* * * * *$

The two contrary tasks of ethics - the enforcement of discipline and the critical deconstruction of disciplinary structures - cohere unstably in the daily practices of all of us. Alongside the contraction of meaning, the pusillanimity, the denials of justice, we also construct new possibilities, create new worlds, new futures and fresh hope.

We grapple with the dissolution of fixed identities and clearly defined value structures, with the changing perspectives and blurred outlines, to find new sources of meaning, new possibilities that well up, as if out of nowhere, from the gaps and spaces that are so perversely generated. We find ourselves listening to the voices of the other, who is now truly other, and hearing sounds where once there seemed to be only silence (Levinas, 1981).

A key and indissoluble task of ethics is to engage against all the odds in dialogues across contrary viewpoints and perspectives. This necessitates openness to difference and an invitation to others to join in the dialogue (Standish, 2001).

Ethical discourse occurs only as a dialogue, and dialogue is only possible when certain conditions are satisfied, including a sense by all the partners of safety and trust. Despite the obstacles, such dialogue is always possible. This is the second paradox of ethics. Not only is communication between contending discourses always available, even those that seem most different, but the more profound the gulf between them the richer and more fecund the play of differences that constitute the dialogue can become (Haste \& Abrahams, 2008; Deleuze, 1988).

The contending tasks of ethics are linked to contrasting technologies and pedagogies. The macro and microtechnologies of discipline and regulation are matched by the rich fecundity of the differences they themselves expose. The disciplinary task calls on a rational policing apparatus linked to constraining and regulating behaviour, to define the boundaries starkly and clarify the outlines. The critical one mobilises the substance of the void between the outlines and seeks systematically to utilise them to generate new possibilities of shared meaning and interaction.

Like its disciplinary shadow, the reconciliatory force of ethics can be nurtured and cultivated. Its pedagogy is not instrumental: there is no algorithm to guarantee ethical exchange; there is no such thing as a "communication skill". However remarkable, there is nothing exceptional about the educational process, because it is always known and available to us, through the fluidity of speech and everyday relationships and the natural competencies on which we daily draw in ordinary life.

It is possible to describe systematically how one undertakes the process of ethical conversation. Such an account would explain the use of the special resources of language, the conscious application of its critical functions, and its performance as utterances in social situations.

Contrary to the claim implicit in the concept of incommensurability, effective communication can always be established across large scale barriers: the barriers of narrative voice and life world, of philosophical assumption and epistemological difference, and of deep cultural and geographical distance. There is always the possibility of 
a common making sense, of a mutually enriching contact, of enhanced respect and understanding, of communication (Komesaroff, 2008).

There are many modalities of cross-discursive communication, although they are not explained by the formal process of translation and there are no hermeneutic rules or algorithms to guide their realization. In part, they include the utilization of the sources of ambiguity at the edge of propositional speech: those devices, rhetorical forms, figures and tropes generally eschewed by philosophers and scientists but embraced by poets and creative writers.

The connection that is established is through language, not as an external tool or artificial device but immanently, as the medium of communication itself. There is no voice for language; rather, language is always already a trace and infinite self-transcendence. In other words, as Agamben has put it, language, which is in the beginning, is the nullification and deferral of itself, and the signifier is none other than the irreducible cipher of this ungroundedness (Agamben, 1999).

One must admit that there is in speech a relationship with a singularity located outside the theme of the speech itself, a singularity that is not thematised by the speech but is indirectly approached by it. Speech and its logical work unfold not through a formal knowledge of the interlocutor but out of his proximity. Thus speech is not a solitary or impersonal exercise of a thought. In Levinas' words, speech establishes"proximity between me and the interlocutor, and not our participation in a transparent universality. Whatever be the message transmitted by speech, the speaking is contact" (Levinas, 1990).

The meaning that is produced, that emerges from the process of dialogue between discrepant discourses, is different from the pre-existing meanings embedded within each of them. The process of communication, or dialogical contact, is not one of pure translation but of the actual generation of new meaning within the specific syntactical, semantic and pragmatic contexts of the distinct discursive unties. It has been argued-by Walter Benjamin and others - that this is in fact the nature of the process of translation in general. The person communicating across discourses introduces into language a kind of "stuttering", which is not simply a stuttering in speech, but a stuttering of the language itself. The task of the translator is to find an effect upon one's own language which produces in it the echo of the original. In individual languages, meaning is in a constant state of flux. Behind the notion of the word itself, as a solid tool rather than as a collection of meanings, must be placed a notion of the way such a word is regarded as a member of the language. This however, is darker and less communicable in any terms other than its own (Benjamin, 1969).

It is important not to treat the hard won forms of agreement as purely affirmative, or as overcoming or sublating disagreement. There is no universal language. Contemporary thought has, after all, recognized that a final and absolute metalanguage does not exist and that every attempt to construct one is caught in an infinite regress. The paradox of pure theoretical intention is precisely that of a discourse that must speak of language, exposing its limits without making use of a metalanguage. However, in reality, language is the absolute, and maybe the only, presupposition (Agamben, 1999).

There are strong arguments in favour of the proposition that, according to any reasonable criteria, ethics pedagogy in medicine and the health sciences has failed. Our reflections highlight the need for educational approaches that do not merely reproduce the moral assumptions and prejudices of the mainstream culture but are faithful to the actual practices of clinical decision making, which contribute to the cultivation of multidimensional competencies covering the many levels of personal and social experience. The competencies required are not outcome or virtue focused; rather, they should be directed towards the facilitation of complex, novel, unobstructed dialogues. Ethics pedagogy in medicine that is true to the nature and needs of the clinic would not seek to implement "curricula" or to run through stereotyped lists of topics but to raise critical questions about the concepts underlying curriculum-based educational strategies.

Inevitably, the most important teaching will continue to be conducted around the bedside in a practical and reflective setting. Such sessions will continue to engage with patients and then reflect on the interactions. As in the past, the lessons will re-enact the conventionalised relationships of medicine, but they will often also contain unruly moments that pose novel, challenging, and even confronting questions (Komesaroff, 2014a; Komesaroff, 2014b). Through them, students will learn what is expected of them, but they will also come to know themselves, and the deep and uncontrollable complexity of the craft into which they are entering. 
We stand round the bed of an 84-year-old man who is dying of AIDS. He is frail and wizened but his mind and voice are clear. He tells us about what he himself refers to as his life of sin. From a young age he had sought all possible pleasures of the senses, without boundaries or limitations. He took drugs, he drank, he partook of pornography. He had innumerable sexual partners, he says, male and female. If he heard about a place of debauchery or a perverse practice he could not wait to try them out himself. Without prompting, he describes incidents, events, parties he attended. He tells us about the joys of anal sex, becoming floridly graphic and detailed in his descriptions. He tells us about how he recently established contact with a daughter he hadn't even known he had had.

He responds matter of factly to our questions about his physical conditions and his emotional life. I ask him if he has ever loved or been loved and he says no. A student asks him if he has any regrets, any fears, at this late time in his life. He tells us that he had made his decisions consciously and deliberately. He had chosen not to follow any morality. He had lived his life for momentary pleasures alone. He had never followed any religion and did not believe in God. He admitted that he was now a bit scared but accepted that this was the life he chose, stating that he was ready to accept the consequences.

We thank him for sharing his philosophy of life with us and retire to the seminar room for a debrief. Some of the students are ashen and perspiring with shock and amazement. I tell them about Faust and Mephistopheles.

\section{References}

Agamben, G. (1999). Potentialities. Redwood City, California: Stanford University Press.

Bauman, Z. (1985). Life in fragments: Essays in Postmodern Morality. Oxford: Blackwells.

Benjamin, W. (1969). Illuminations. New York, NY: Schocken.

Eckles, R. E. et al. (2005). Medical Ethics Education: Where Are We? Where Should We Be Going? A Review. Academic Medicine, 80, 1143-1152. http://dx.doi.org/10.1097/00001888-200512000-00020

Feudtner, C., \& Christakis, D. A. (1994). Making the Rounds. The Ethical Development of Medical Students in the Context of Clinical Rotations. Hastings Center Report, 24, 6-12. http://dx.doi.org/10.2307/3562379

Fox, R. (1979). Essays in Medical Sociology: Journeys into the Field. New York: John Wiley and Sons..

Gilligan, C. (1982). In a Different Voice. Cambridge, Massachusetts: Harvard University Press.

Giroux, H. (1989). Schooling as a Form of Cultural Politics: Toward a Pedagogy of and for Difference. In H. A. Giroux, \& P. McLaren (Eds.), Critical Pedagogy, the State, and the Struggle for Culture (pp. 125-151). New York: State University Press of New York.

Habermas, J. (1976). Moral Development and Ego Identity. In T. McCarthy (Ed.), Communication and the Evolution of Society (pp. 69-94). Boston: Beacon.

Hafferty, F. W. (1991). Into the Valley: Death and the Socialisation of Medical Students. New Haven, CT: Yale University Press.

Hafferty, F. W., \& Franks, R. (1994). The Hidden Curriculum, Ethics Teaching, and the Structure of Medical Education. Academic Medicine, 69, 861-871. http://dx.doi.org/10.1097/00001888-199411000-00001

Haste, H., \& Abrahams, S. (2008). Morality, Culture and the Dialogic Self: Taking Cultural Pluralism Seriously. Journal of Moral Education, 37, 377-394. http://dx.doi.org/10.1080/03057240802227502

Heller, A. (1999). A Theory of Modernity. Cambridge, MA: Blackwell Publishers.

Irigaray, L. (1993). An Ethics of Sexual Difference. Trans. Burke, C., \& Gill, G.C. Ithaca, NY: Cornell University Press.

Kohlberg, L. (1984). The Psychology of Moral Development: The Nature and Validity of Moral Stages. Essays on Moral Development (Volume II). San Francisco, CA: Harper \& Row Publishers.

Komesaroff, P. A. (2008). Pathways to Reconciliation: Bringing Diverse Voices into Conversation. In P. Rothfield, C. Fleming, \& P. A. Komesaroff (Eds.), Pathways to Reconciliation: Between Theory and Practice (pp. 1-14). Farnham: Ashgate.

Komesaroff, P. A. (2014a). Experiments in Love and Death. River Grove, IL: River Grove Books.

Komesaroff, P. A. (2014b). Riding a Crocodile: A Physician's Tale. Perth: University of Western Australia Press.

Levinas, E. (1961). Totality and Infinity: An Essay on Exteriority. Trans. Lingis, A. (Section 1, Part C). Pittsburgh, PA: Duquesne University Press.

Levinas, E. (1981). Otherwise Than Being or Beyond Essence. Trans. Lingis, A. Pittsburgh, PA: Duquesne University Press. 
Levinas, E. (1990). Philosophical Essays. The Hague: Martinus Nijhoff.

Pellegrino, E. D., Hart Jr., R. J., Henderson, S. R., Loeb, S. E., \& Edwards, G. (1985). Relevance and Utility of Courses in Medical Ethics. A Survey of Physicians' Perceptions. Journal of the American Medical Association, 253, 49-53. http://dx.doi.org/10.1001/jama.1985.03350250057022

Peterson, M. J. (1978). The Medical Profession in Mid-Victorian London. Berkeley, CA: University of California Press.

Smith, D. W. and Greco, M. A. (1998). He Stuttered. In G. Deleuze (Ed.), Essays Critical and Clinical (pp. 107-114). New York: Verso.

Standish, P. (2001). Ethics before Equality: Moral Education after Levinas. Journal of Moral Education, 30, 339-347. http://dx.doi.org/10.1080/03057240120094832

Taylor, C. (1992). Modernity and the Rise of the Public Sphere. The Tanner Lectures on Human Values. http://tannerlectures.utah.edu/_documents/a-to-z/t/Taylor93.pdf 